\title{
LONG-TERM STUDIES OF WILLOW PTARMIGAN AND GYRFALCON IN THE YUKON TERRITORY: A COLLAPSING 10-YEAR CYCLE AND ITS APPARENT EFFECT ON THE TOP PREDATOR
}

\author{
Dave H. Mossop \\ Yukon Research Center, Yukon College, Box 2799, \\ Whitehorse, Yukon, Canada, Y1A 5K4.E-mail: dmossop@yukoncollege.yk.ca
}

\begin{abstract}
From the late 1950s to the present, several study plots across the Yukon have been variously surveyed annually for territorial Willow Ptarmigan (Lagopus lagopus). Beginning in the mid-1970s, Gyrfalcon (Falco rusticolus) breeding numbers in the same tundra systems have been monitored annually. These data are held in a long-term data base. Monitoring has supported studies of winter survival strategies, tests of population change theory, and reproductive strategy. Willow Ptarmigan are seen as a 'keystone' in the tundra community. Understanding and tracking very basic trophic interrelationships with the Gyrfalcon, the top predator, has been a major effort at community study. Stable, regular, synchronous, 10 -year cycles have been demonstrated in both species. However, beginning in 2000 , monitoring surveys have been suggesting the regular cycling of ptarmigan abundance may be faltering - the population peaks seem to be disappearing, although there is no evidence of imminent local extinctions. The potential consequence to the tundra ecosystem is suggested in disruption at the top of the food chain-Gyrfalcons are breeding much later, may be producing fewer young, and seem to be declining in abundance. Simple modeling suggests Gyrfalcon productivity through the few years of peak ptarmigan productivity may be critical. It will be important to maintain longer monitoring to demonstrate conclusively this change as well as causes. Received 31 December 2010, accepted 20 June 2011.
\end{abstract}

Mossop, D. H. 2011. Long-term studies of Willow Ptarmigan and Gyrfalcon in the Yukon Territory: A collapsing 10-year cycle and its apparent effect on the top predator. Pages 323-336 in R. T. Watson, T. J. Cade, M. Fuller, G. Hunt, and E. Potapov (Eds.). Gyrfalcons and Ptarmigan in a Changing World, Volume I. The Peregrine Fund, Boise, Idaho, USA. http://dx.doi.org/ 10.4080/gpcw.2011.0206

Key words: Gyrfalcon, Willow Ptarmigan, population cycles, climate change, trophic level, community.

TUNDRA ECOSYSTEMS are thought to be under particular threat of damaging alterations from global climate changes (Bonsal and Kochtubjada 2009, Lean and Rind 2009). Exactly what these changes will be is confused by a variety of seemingly convincing analytical, yet differing, predictions. Some insist on drying, others on wetting; some on earlier springs, others on later springs, and so on. Whatever the ultimate changes, because the living communities of the tundra are relatively simple, they may offer one of the best hopes for making some sense of how natural communities, with their complex trophic levels, intricate food webs, and interacting niches, can respond and hopefully adapt to global change. 
At the top and bottom of the food chain involving medium-sized species in western arctic tundra communities are a keystone species, the Willow Ptarmigan (Lagopus lagopus), and a top predator, the Gyrfalcon (Falco rusticolus). Interestingly, long before talk of global climate changes, several Willow Ptarmigan populations began to be visited almost annually in the Yukon and adjacent tundra, to track their fortunes and periodic fluctuations. This early work was largely in support of other research into population ecology and continues to this day for that reason (Weeden 1959, Mossop 1988). As a by-product, it now spans over 40 years, one of the longest-term continual data sets monitoring a tundra population anywhere. Companion to that work, again pre-dating climate change warnings, three Gyrfalcon populations have been monitored: one annually for almost 30 years, the other two much less faithfully.

These data sets represent a unique opportunity to explore the potential for illuminating the nature of community disruptions in these ecosystems. We already know a great deal about the functioning of the two natural populations involved (Mossop 1988, Mossop and Hayes 1994), and we have some valuable contributions to understanding how the interrelationships between them may function (Barichello and Mossop 2011). By far the most obvious and overarching observation of these populations and, presumably, the whole trophic regime of these tundra communities, is the classic 10-year cycle of abundance they exhibit. This, along with the generally stable long-term mean population sizes for both the predator and prey of this food chain, has been known for many years (Mossop 1988, 1994).

In exploring ideas about the effect of community disruption, the foundation of hypothesis is predictability. The central thesis I have pursued with these data sets in past decades has been that, if ecological systems become unpredictable or erratic in their annual presentation, this should be reflected in poor performance at the top of the food web. Tracking Gyrfalcon population performance in concert with ptarmigan numbers, and comparing both to pre-climate change years, should provide that test.

\section{Study Design}

I have monitored ptarmigan populations using up to seven study plots, widely spaced across Yukon ecoregions. Situated in classic Willow Ptarmigan habitat, they have been variously visited and searched in early spring for territorial pairs. Three of these have sufficient data to figure in this analysis, and I have visited most faithfully the southernmost, virtually annually (Figure 1). In the first week of May, when snow cover is still $100 \%$, adult males are in their most obvious spring plumage, and all pairs are spaced on defended areas. During this period, one to several field workers on skis or snowshoes systematically covered the $1-\mathrm{km}^{2}$ study plots and made a total count of territorial pairs, including, if present, lone territorial males. The third area, on the North Slope, I have surveyed using transects flown at low-level by helicopter across tundra habitat (Bergerud and Mercer 1966). Early work involved color-banding territorial birds, in part to establish certainty of territory fidelity (Mossop 1988). Later focus was on the two best known study plots, with the North Slope data used mostly as ancillary support. The southernmost area (located $59^{\circ} 43^{\prime} \mathrm{N}$, $136^{\circ} 35^{\prime} \mathrm{W}$ ) is just south of the southern Yukon/ northern British Columbia border in the YukonStikine Highland ecoregion (Smith et al. 2004). It has been monitored annually since the mid1950's (Weeden 1965, Mossop 1988). The other, in the middle Yukon $\left(64^{\circ} 43^{\prime} \mathrm{N}\right.$, $\left.138^{\circ} 15^{\prime} \mathrm{W}\right)$, is in the Mackenzie Mountains ecoregion and has been monitored since 1970 . Given early work on understanding these ptarmigan populations, their habitat selection, winter survival strategies, and population dynamics (Weeden 1965, Mossop 1988), there is a high degree of confidence in the accuracy of the monitoring data.

Companion to these ptarmigan study areas has been intensive monitoring of Gyrfalcon num- 
bers within the same ecoregions. As with the ptarmigan study, this monitoring effort has supported research into the population ecology of these birds (Barichello 1983, Mossop and Hayes 1982). Similarly, as a by-product, these long-term data sets can now be used to track the fortunes of the community itself, given the Gyrfalcon as a top predator and classic 'indicator' focal species. The work of Barichello (2011) is pivotal in this regard, establishing as he does, the critical relationship between ptarmigan and Gyrfalcons. Basically, in late winter when Gyrfalcons are producing their clutches, ptarmigan are literally the only prey species on their habitat. This total dependence changes later in the year, but during that critical time, the two species are completely and intimately interconnected.

To inventory and monitor Gyrfalcon performance, I and others working with me used helicopters to search large $\left(15,000\right.$ to $\left.26,000 \mathrm{~km}^{2}\right)$ areas within the ecoregions involved (Figure 1). We completely searched every drainage and mountain block, and closely inspected all cliff faces for occupying adults, as well as for telltale whitewash and lichen deposit indicative of occupancy by birds of prey (Mossop and Hayes 1994). I considered a cliff face or series of cliffs occupied by a breeding pair of adults as indicating a defended territory and gave it a permanent identifier in the data base. On return monitoring flights, the known occupied cliff faces were used as a survey pattern. A survey was a single visit at a time designed to coincide with young about 15-25 days of age. In practice, most sites were resurveyed by helicopter, and a very few (4) were accessible by foot. Also, in practice, a sample of territories was selected that could be predictably and adequately observed. By far, the most faithfully monitored population was the southern one, where a minimum of 19 sites constituted the sample group (from a total population of 32 historically known territories). The basic demographic data collected was: a) occupancy by adults, b) any production effort, and c) number of young near fledging. Depending on

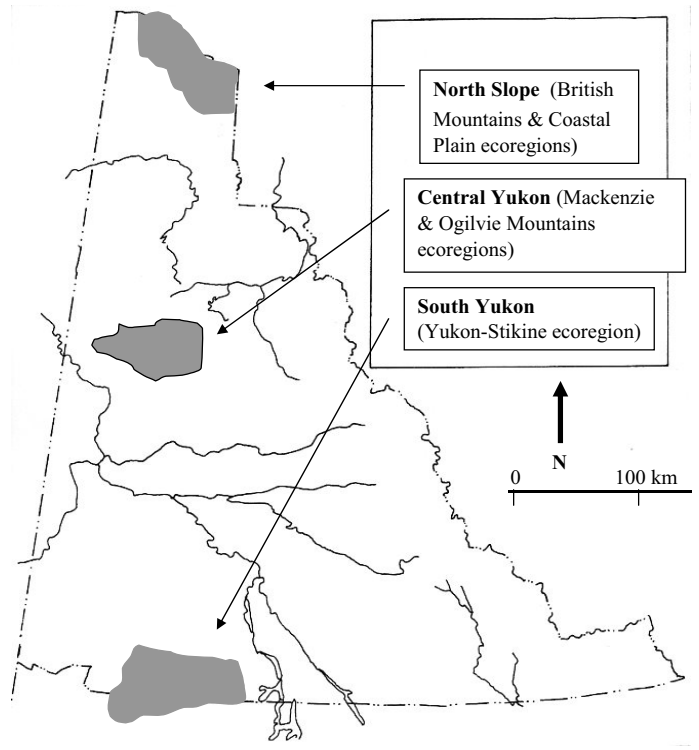

Figure 1. The Yukon Territory and the three principal study areas. The southern area in the Yukon-Stikine ecoregion is about $15,000 \mathrm{~km}^{2}$. The central area in the Mackenzie Mountain and North Ogilvie ecoregions is about $18,000 \mathrm{~km}^{2}$ and the North Slope area straddling the BritishRichardson Mountains and Coastal Plain ecoregions is about 26,000 km². Gyrfalcon data cover the whole areas; Willow Ptarmigan data are from plots or transects roughly in the centers of the areas.

the year and ancillary studies involved, prey remains, blood samples, feather samples, and nest site measurements were also collected.

\section{INTERPRETING FIELD DATA}

I have assumed, based on intensive annual field work with both species, that survey timing has been adequate to determine the breeding population in any one year. I have also assumed, based on my sampling within known critical habitat, that long-term occupancy of the monitored areas can be expected. In the case of the Gyrfalcon, I have been monitoring nesting territories that represent over half the known population in the ecoregion, as determined through many years of total intensive search. My sample thus offers adequate extrap- 
Figure 2. Willow Ptarmigan population densities from three widely spaced habitats across the Yukon. The top two are from $1 \mathrm{~km}^{2}$ plots, the bottom from transect survey.

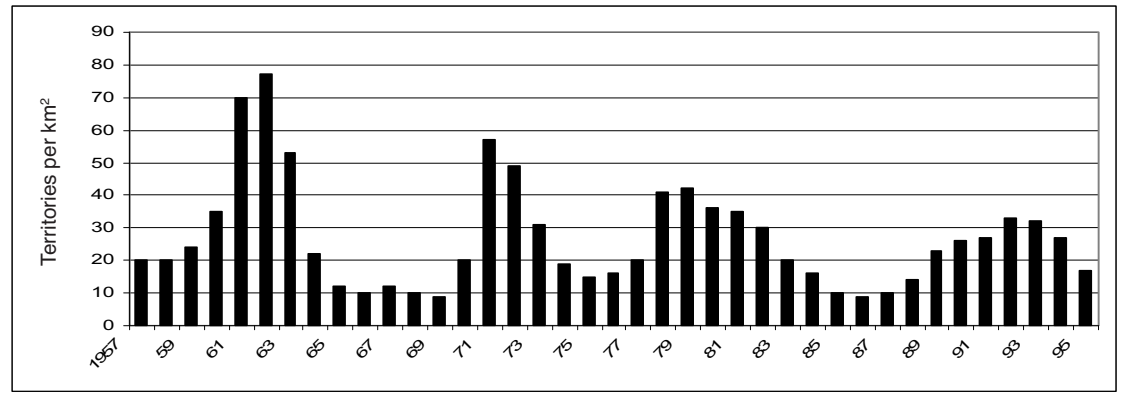

Southern population: Yukon-Stikine ecoregion

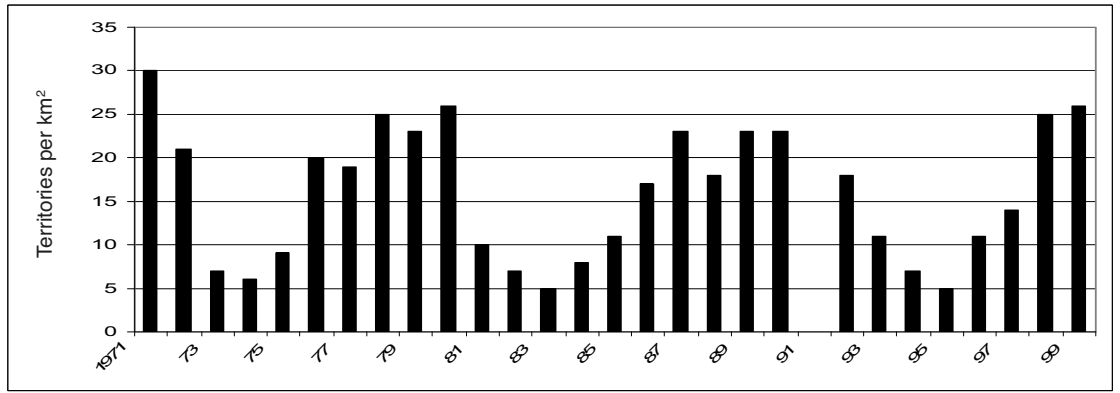

Mid-Yukon population: Mackenzie-Ogilvie ecoregions

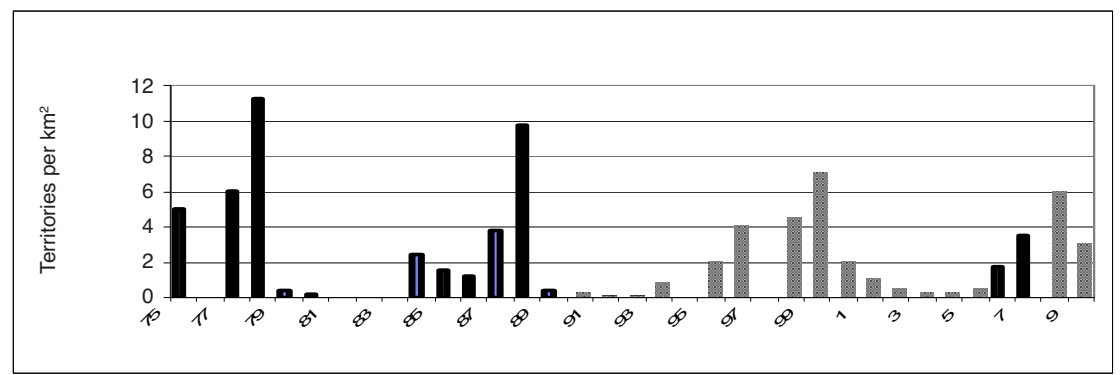

North Slope population: British Mountains-Coastal Plain ecoregions (black bars are counts, grey bars are estimates from local residents) olation to the whole population. Equally, I have assumed that the cliff faces can be searched and re-monitored with equal confidence as a measure of adult Gyrfalcons on the land (Barichello 1983). Interpreting Gyrfalcon occupancy when no adults were actually observed does pose additional problems. In that case, I have assumed that obviously fresh guano at the site indicates an occupied nest site in that year, but that if the same observation was made three years in sequence, I have assumed an unoccupied nest site, a conservative assumption that may underestimate the breeding population.
Most population data are from single annual surveys, making accuracy difficult to quantify. However, based on repeated surveys during earlier research into the population ecology of both species, accuracy is assumed to be at least $90 \%$. To track population performance across multiple fluctuations, I have used an 'effective breeders' calculation across each fluctuation which allows comparison of population performance over several decades: N+1/(1/n+...1/n) (Primack 2006). 
Table 1. Cyclic parameters of Willow Ptarmigan populations (90\% C.I.) measured in study plots across the Yukon Territory, Canada, 1960-2010 ("Period" refers to cycle duration in years; "Mean" and "Peak" numbers are territories per km²; "Of Mean" and "Of Mean Low" refer to multiples of the mean).

\begin{tabular}{lrrccc}
\hline Study Area & Period & Mean & Peak & Of Mean & Of Mean Low \\
\hline N. Slope & $10+1.7$ & 3.0 & $9.3+2.1$ & $3.2 X$ & $31 X$ \\
Central Yukon & $9.7+0.7$ & 15.3 & $26.3+2.1$ & $1.7 X$ & $5 X$ \\
S. Yukon & $9.0+2.2$ & 27.1 & $53.8+17$ & $2.0 X$ & $4.1 X$ \\
\hline
\end{tabular}

\section{Results}

Ptarmigan Numbers.-Between 1955 and 1990, the southern population maintained between 10 and 80 territories per $\mathrm{km}^{2}$ and has demonstrated four obvious cycles of abundance; the first peak in approximately 1960 , then the three following, equally spaced, in the subsequent decades (Figure 2). The central Yukon population has fluctuated between 5 and 30 territories per $\mathrm{km}^{2}$. That data set began with a 1970 peak, followed by peaks in the next two decades in apparent fairly close synchrony with the southern population. The North Slope population has varied between an extremely low number (undetectable by my measure) to about 11 territories per $\mathrm{km}^{2}$. Approximate synchrony was noted through this period with the other plots in the Yukon, as well as with the Yukonwide harvest statistics across the suite of grouse species (Mossop 1994).

These cycles of abundance have been recorded in all the various grouse populations across the Yukon that have been surveyed (unpublished data). The three Willow Ptarmigan populations are typical: regular, approximately synchronous cycles, albeit at different average densities. The shapes of cycles have also been obviously different. Key is the size of peak numbers and their size relative to mean population sizes. The more southern population peaked at nearly eight times the size of the most northern population, whereas all seemed to be displaying peaks about two-to-three times the average long-term density. Meanwhile, the relative sizes and abruptness of the peaks were much more striking in the more northern populations (Table 1).

Whatever the ultimate explanation for these regular population changes, they remain as one of the most obvious and potentially critical features of tundra ecology. The most consistent conclusions from research addressing the reasons for the variations in annual densities within these (and other grouse) populations has been the effect of production of young as opposed to the mortality of either young or adults (Bergerud 1988). Moreover, there is growing evidence that spring social behavior has a profound effect on the number of young produced in the subsequent breeding season (Mossop 1988).

Ptarmigan Population Trends.-Over the periods tracked, changes have become obvious mostly in the size of peak populations. I first noted change in the southern population, where the peaks from 1960 to 1980 declined by almost half $(\mathrm{P}=0.095)$. No similar decline was detected in the central population, but on fewer data, a suggestion of a similar decline was apparent on the North Slope (Figure 2).

Secondly and most significantly, both wellmonitored southern populations have demonstrated in the last decade an apparent collapse in the regular, obvious cycle (Figure 3). Interestingly, the mid-Yukon population did not show the anomaly until a full 10 years after it was obvious in the southern population. On the North Slope, estimates (based mostly on impressions among local people) did not suggest obvious disruption in the "10-year" cycle. 
Figure 3. Willow Ptarmigan population fluctuations showing regular 10-year cycles in abundance and the anomalous last decade. Data are from total spring ground counts of one $\mathrm{km}^{2}$ plots in the Yukon, Canada.

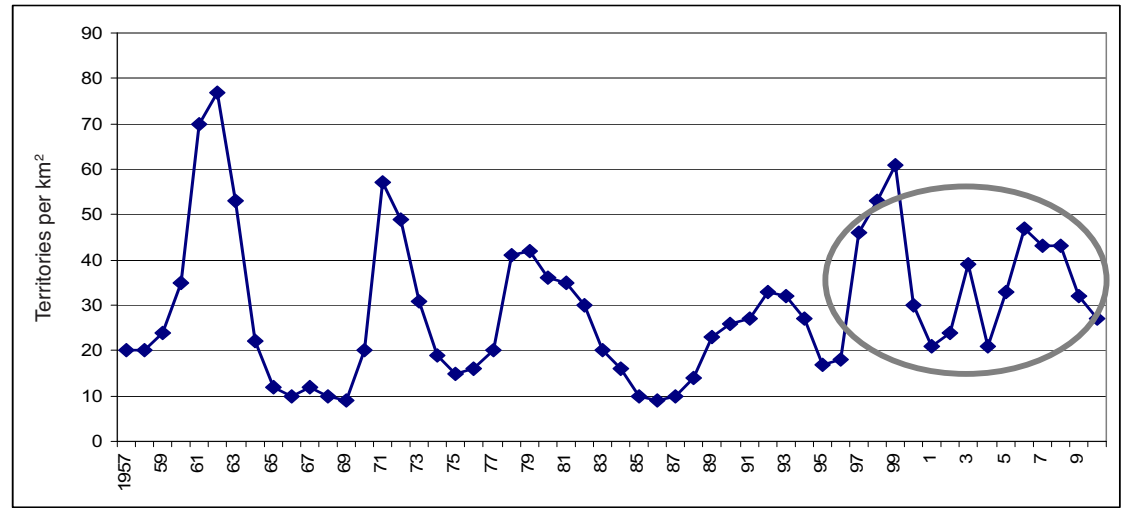

S. Yukon Willow Ptarmigan

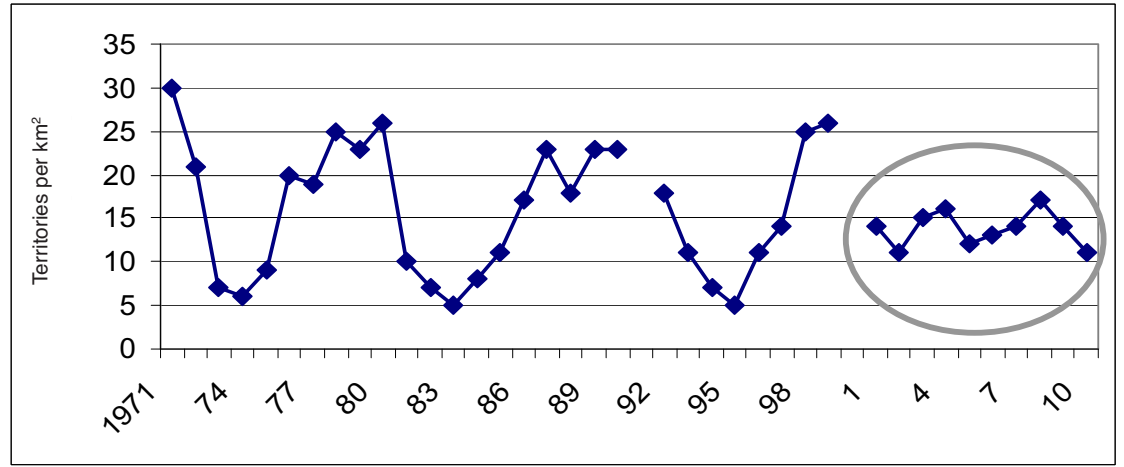

Mid-Yukon Willow Ptarmigan

I have no evidence that these trends will continue in future years. Nor is there evidence that the ptarmigan populations are in any threat of collapsing completely. In fact, calculating the 'effective' breeding population through the cycles shows no significant change even as the peaks in population abundance have disappeared (Figure 4). What has become clear is that the cycling of this 'keystone' prey species has become unpredictable, and this was the prime requirement for the test of community disruption. If the relationship between predator and prey is as close as Barichello and Mossop have shown (2011), there should be significant disruption to the Gyrfalcon population dynamic.

Gyrfalcon Numbers.-The population of Gyrfalcons I have monitored most carefully is the southern group: good annual data exist from
1982 to the present. Its analysis is my prime focus here. The mid-Yukon (Ogilvie Mountain) population was monitored effectively from 1978-83, after which time it has been essentially unmonitored; only two to three nest cliffs have been visited sporadically. I surveyed the North Slope population annually from 1977 through 1991. Then following a 16 year hiatus, I was able to carry out two years of survey: 2007 and 2008.

Population sizes and densities varied significantly between ecoregions (Table 2). All populations in the early years demonstrated cyclic changes in various demographic parameters, but mostly in the proportion of nest sites actually producing young (Figure 5). These cycles effectively mirrored cyclic changes in ptarmigan populations. This suggests agreement with Barichello and Mossop (1983), who first 


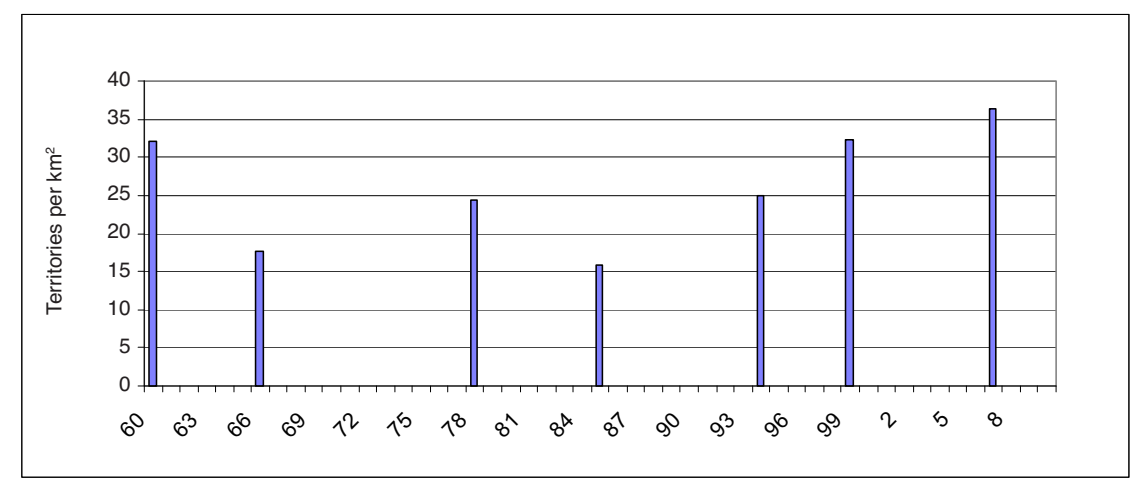

Figure 4. "Effective" breeding pairs across decadelong population fluctuations in Willow Ptarmigan (data from ground counts in spring).

\section{S. Yukon Willow Ptarmigan}

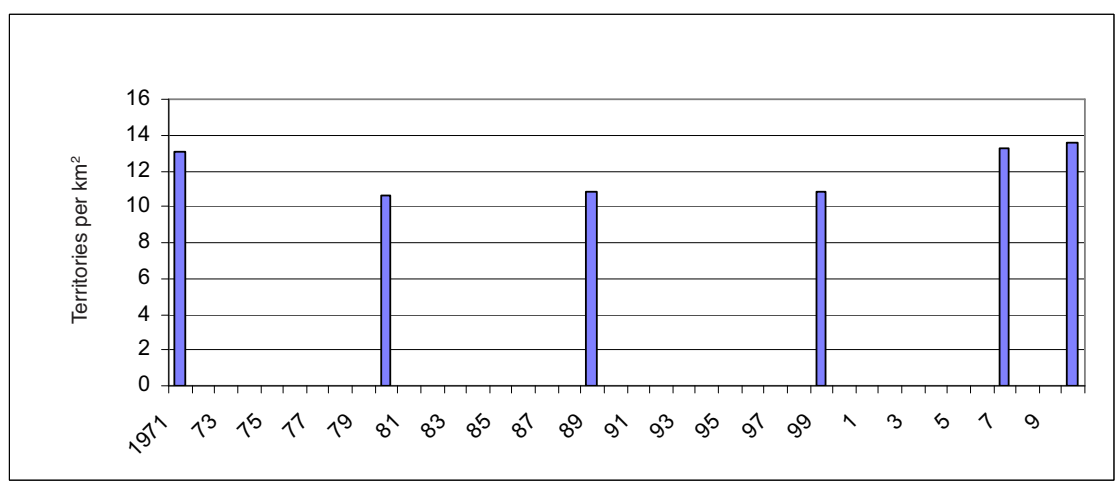

Mid-Yukon Willow Ptarmigan

demonstrated the correlation between the performances of the two species on the midYukon study area. Productivity in the Gyrfalcon population (primarily the number of pairs that produced young) was the key correlate. This finding also seemed to hold on the North Slope through 1991 with a suggestion, albeit based on fewer data, that the relationship may hold to the present.

Gyrfalcon Trends.-Earlier I reported a suggestion of changing nesting chronology in Yukon Gyrfalcons (Mossop and Hayes 1994). Since that time, continued tracking of nesting chronology (based on visual aging of young during survey) has been suggesting more troubling trends. In the early years of annual monitoring of the southern population (1982-1991), breeding seemed to be trending toward an earlier initiation. Then in about 1992, the trend reversed and Gyrfalcons are now apparently breeding in the southern Yukon over two weeks (20 days) later than noted in the earliest surveys (Figure 6).

Changes in the number of nest sites producing young has been a key parameter, tracked faithfully. Again, the southern population is the only one where I have sufficient data. My estimates of the number of adults occupying nest sites is fundamental, but is complicated by my two measures. The less conservative estimate (no adults observed but apparent fresh 'wash') shows only a suggestion of 'faltering,' whereas the more conservative estimate suggests a more troubling disruption (Figure 7). Estimates of the number of young follow suit. Based strictly on a gross comparison between years, it is difficult to see an obvious shift in this measure. However, when all four decades of counts are tracked, and applied to the two measures of the observed adult breeding population, a decline in 
Table 2. Gyrfalcon population size and densities from various ecoregions across Yukon.

\begin{tabular}{lccc}
\hline Survey Area & Area $\left.\mathbf{( k m}^{2}\right)$ & Nest Sites & Density (pairs/1000 $\left.\mathbf{~ k m}^{2}\right)$ \\
\hline North Slope & 26,000 & 120 & 4.6 \\
Mid-Yukon & 18,000 & 58 & 3.2 \\
South Yukon & 15,000 & 36 & 2.4 \\
\hline
\end{tabular}
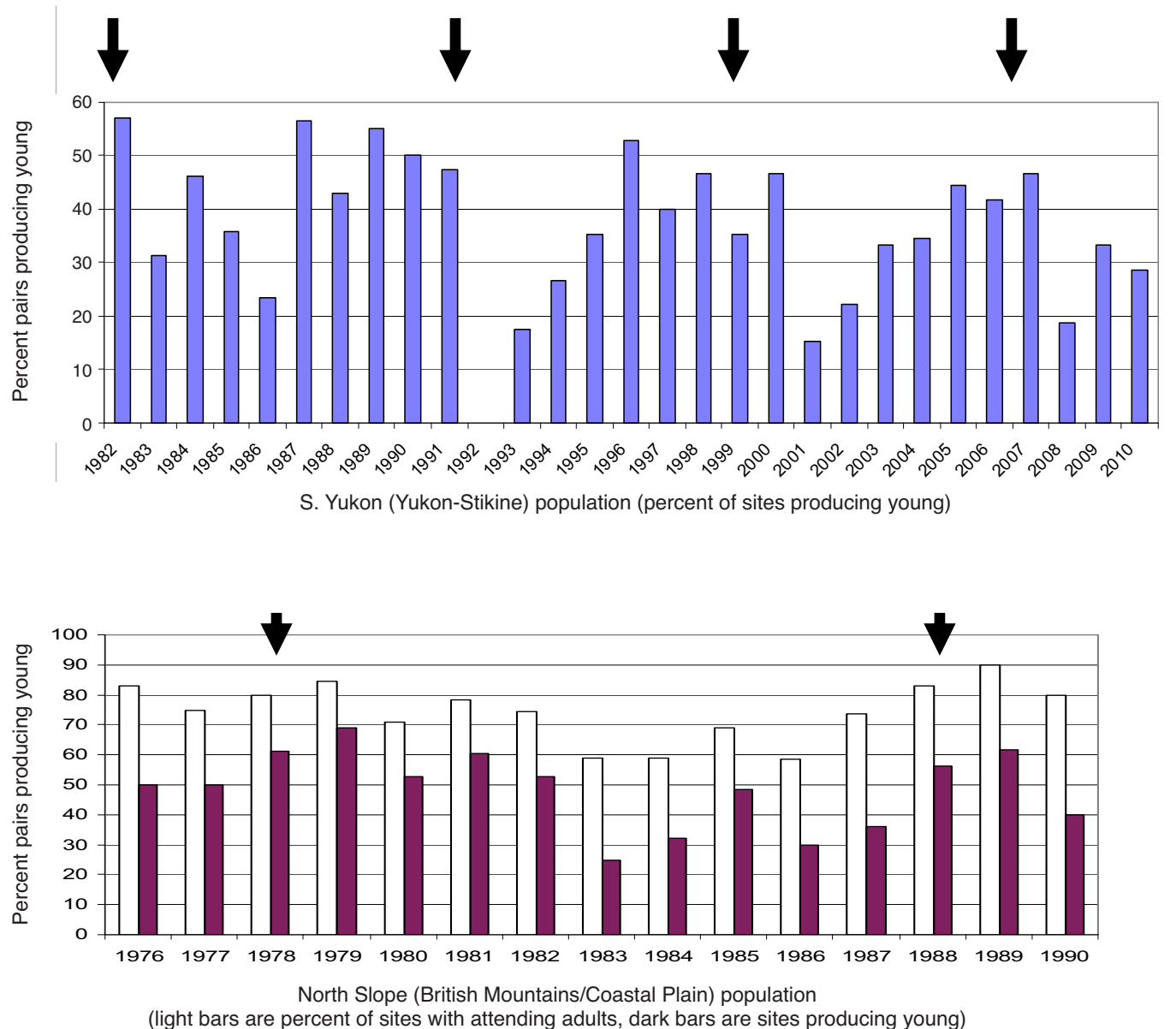

Figure 5. Proportion of surveyed Gyrfalcon pairs producing young in that year; S. Yukon and North Slope populations. Arrows are at the peaks in Willow Ptarmigan breeding density. 

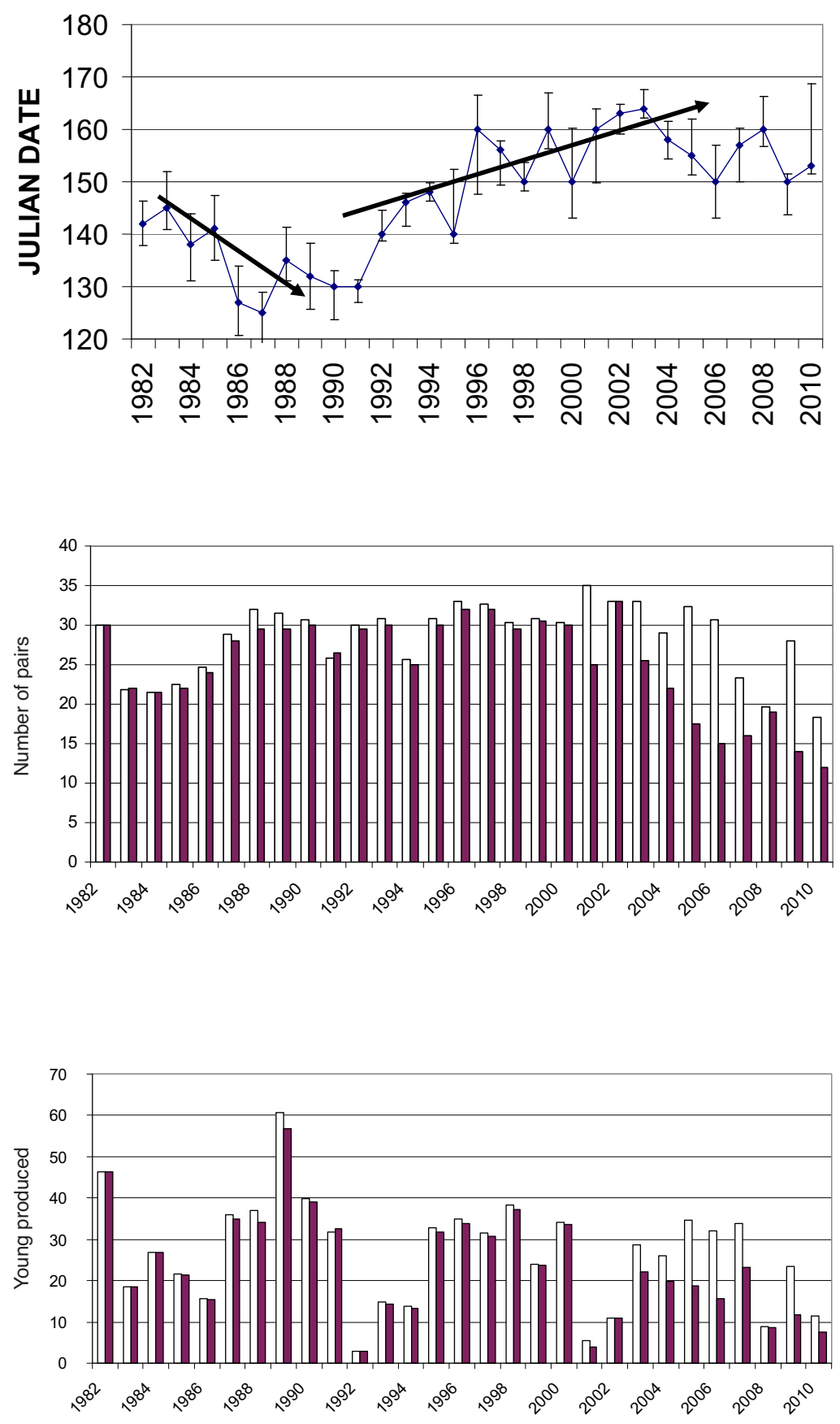

Figure 6. Changing hatch date: S.Yukon Gyrfalcon population (arrows for emphasis only).
Figure 7. Estimates of number of adult pairs of Gyrfalcons annually based on two measures of adult population size: light bars are based on observing fresh wash when no adults were observed, dark bars indicate that site is recorded as 'unoccupied' after three successive years showed no adults. Data from S. Yukon population (Yukon-Stikine ecoregion).

Figure 8. Estimates of young Gyrfalcons being produced annually in S.Yukon population, based on 32 historically active nest sites across the Yukon-Stikine ecoregion. Light bars are based on observing fresh wash when no adults were observed, dark lines when three successive years showed no adults. 
Figure 9. Percent "effective" breeding pairs of Gyrfalcons through five 10 year cycles, 90\% C.L. The initial cycle is represented by data from only the last half of a decade period.

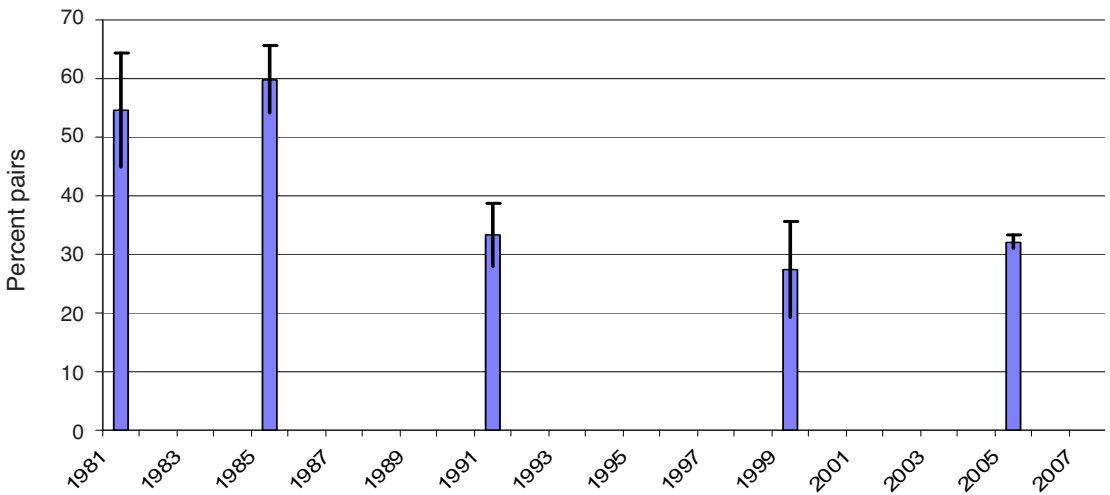

productivity is apparent (Figure 8). The decline shown by the conservative measure of adult occupancy is significant, but by the more liberal estimate it is not. Although with fewer data, the productivity of the North Slope population seems similar. Further, calculating the proportion of "effective" breeders across decadal cycles in the southern population (Figure 9) shows a significant decline beginning about the time the much reduced 1990 ptarmigan population peak was recorded (see Figure 3).

\section{Discussion}

Trophic interactions across natural communities, although in theory well known, have received very little experimental attention in field study (Berryman 2002). My field research, although clearly leaning toward understanding that food web architecture is essential to population dynamics in natural communities, was not designed as an experimental test of the specifics of the "necessary and sufficient" explanations (Chitty 1960). My analysis of these long-term data sets from the Yukon tundra systems are mostly a series of natural history-based observations suggesting that disruption is happening, that this disruption is likely occurring within lower trophic levels of the community, and is impacting the top predator. Interestingly, most analyses of trophic effects in natural populations seem to be designed to test the ideas that top predators are driving what we see in lower levels (Krebs et al. 1993), whereas those with a prime interest in the fortunes of top predators tend to see things from the other side: how prey populations explain predator populations. We tend to drift toward hypotheses that see lower trophic level populations either 'self-regulating' or at least being functionally regulated by processes without undue reference to things eating them (Chitty 1967).

A central contention of those of us concerned about human-caused changes (such as climate) to broad ecological systems is that natural communities and their component populations have evolved around the predictability of those conditions. The complex nature of these interactions may not be totally understood for decades. Meanwhile disruption is definitely happening, and our close attention is warranted to attempt a better understanding of how those interactions function. Shouting a warning toward stopping those disruptions may be a healthy response, even if the result is in some doubt (Solomon et al. 2009). It is important, in this regard, to note that predictability does not necessarily denote ambient stability.

Boreal systems have for decades impressed on even casual observers that perhaps a central predictability within the biome is the cyclic nature of populations within it. I refer, in particular, to the '10-year' cycle (Keith 1963), whereas other phenomena, such as the cyclic nature of anadromous fish returns (Cederholm et al. 1999) provide periodic huge 'rushes' of 


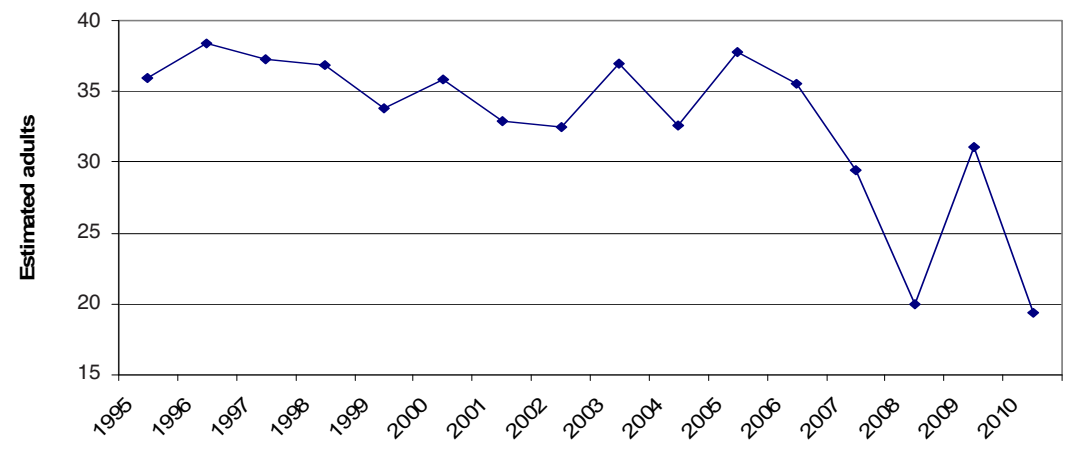

Figure 10. Predicted adult Gyrfalcon population in subsequent years, based on observed production of young and assuming $10 \%$ annual adult mortality, $75 \%$ mortality of young before recruiting at 3 years (S. Yukon population).

nutrients to relatively impoverished boreal ecosystems. It is completely logical that boreal populations and their communities would, over time, become adapted to deal with this periodic, predictable phenomenon (Millon et al. 2008, Stenseth et al. 1997). Although I am convinced the Yukon data sets show a serious disruption in the 10-year cycle in the abundance of Willow Ptarmigan, there is no way to know if the next decade will see its return to normality. Supporting the prospect of loss is the growing evidence that, elsewhere in the boreal systems, population cycles are also ceasing (Ims et al. 2008).

The most compelling evidence from the Yukon data is the apparent loss of the "peaks" in ptarmigan numbers. However, I have no evidence that ptarmigan populations are disappearing. To the contrary, calculations of 'effective breeders' through all decades show no change. The ultimate effect this may have on ptarmigan population ecology must await a distant future analysis. Meanwhile, Gyrfalcons are faced with a very different prey base. If Barichello and I are correct, the proportion of yearling ptarmigan in the late winter-early spring population best explains Gyrfalcon production that year. Additionally, if Bergerud (1988) and others (Mossop 1988) are correct, the production of young ptarmigan in any one year predicts population size in the next. It follows that a 'faltering' ptarmigan population failing to rise to 'peaks' is simply not producing adequate young to do so. Growing concern is mounting from climate watchers in the north as well as from local people on the land, that the key influence may be a worsening of late winter-early spring weather. Winters are becoming noticeably milder in the northwest, spring thaws are coming very early, but then spring cold and wet weather persist. Many anecdotal observations across the western arctic and sub-arctic seem to suggest that ptarmigan nests and broods are being affected. In theory, the Gyrfalcon, a long-lived predator, has evolved to use the periodic 'rushes' of prey in order to produce the young necessary to fill gaps in the population during the 'lean' years. Losing the peak of ptarmigan numbers, by this logic, should present the Gyrfalcon reproductive strategy with an insurmountable dilemma. The possibilities facing the predator in this case are either to readjust population size downward (which seems to be what is happening over the short term) and/or to adapt by forgoing reproduction until very late in the season when other prey become available (which also seems to be happening). An appreciation of the long-term consequences awaits a future monitoring effort.

A simple modeling of Gyrfalcon population performance based on the limited parameters being tracked with field data, and inserting assumptions from other raptor studies (mostly of mortality rates: Newton 1979), can help a bit with understanding future fortunes of the Gyrfalcon. In Mossop and Hayes (1982), preliminary predictions based on initial data were 
mostly useful in impressing on managers the very delicate relationship between Gyrfalcon productivity and ptarmigan population performance. Repeating that analysis with current data corroborates that conclusion and strongly suggests that the declining breeding population I think I am seeing in my field data is predictable and real (Figure 10).

Efforts in the developing discipline of Conservation Biology are, by necessity, well known for being well out in front of the definitive science. The frustration of analyzing long-term trends that $I$ and others are experiencing is that the time needed to test hypothesis with experiment simply may not be available. There is no way to know if we are tracking a disaster into the future or simply a unique one-time loss of a cycle. In any case, it is becoming clearer that even single-cycle disruption within this food web is discernable, and its consequence at the top, in terms of the relative affect on population performance, seems to be many times greater than that seen in the prey population.

\section{ACKNOWLEDGMents}

Many field workers have been involved in the survey and monitoring of bird populations in the Yukon. Bob Hayes was one of the principals, Kerry Guenter, Kathy Egli, Norm Barichello and Wayne Nelson made important contributions. The World Wildlife Fund, the Canadian federal Public Works Department, and the governments of the Yukon and British Columbia have made survey budgets possible, and government biologists Bill Munroe, Myke Chutter, and Rob Florkiewcz contributed field effort. Thanks are especially due to Norm Barichello and Grainger Hunt for constructive comments on the manuscript. Tom Cade has been a great source of encouragement through the years. Thanks is also due to The Peregrine Fund, through which I was able to travel to present the work.

\section{Literature Cited}

B ARICHELLO, N. 1983. Selection of nest sites by Gyrfalcons (Falco rusticolus). M.S. thesis, University of British Columbia, Vancouver, Canada.

BARICHELLO, N. 2011. Gyrfalcon courtship-a mechanism to adjust reproductive effort to the availability of ptarmigan. In R. T. Watson, T. J. Cade, M. Fuller, and W. G. Hunt (Eds.). Gyrfalcons and Ptarmigan in a Changing World. The Peregrine Fund, Boise, Idaho, USA. http://dx.doi.org/ 10.4080/gpcw.2011.0208

B ARichello, N., AND D. H. Mossop. 1983. Productivity of Gyrfalcons (Falco rustico$l u s$ ) as a response to changes in the ptarmigan (Lagopus spp) abundance over a five year period. Proceedings $34^{\text {th }}$ Arctic Science Conference, Whitehorse, Canada.

B ARICHEllo, N., AND D. H. Mossop. 2011. The overwhelming influence of ptarmigan abundance on Gyrfalcon reproductive success in the central Yukon, Canada. In R. T. Watson, T. J. Cade, M. Fuller, and W. G. Hunt (Eds.). Gyrfalcons and Ptarmigan in a Changing World. The Peregrine Fund, Boise, Idaho, USA. http://dx.doi.org/ 10.4080/gpcw.2011.0205

Bergerud, A. T. 1988. Population ecology of North American grouse. Pages 578-684 in A. T. Bergerud and M. Gratson (Eds.). Adaptive Strategies and Population Ecology of Northern Grouse. Univerity of Minnesota Press, Minneapolis, Minnesota, USA.

Bergerud, A. T., AND W. E. Mercer. 1966. Census of the Willow Ptarmigan in Newfoundland. Journal of Wildlife Management 30:101-13.

Berryman, A. 2002. Population Cycles, the Case for Trophic Interactions. Oxford University Press, New York, USA.

Bonsal, B., AND B. Kochtubjada. 2009. An assessment of present and future climate in the Mackenzie Delta and the near-shore Beaufort Sea region of Canada. International Journal of Climatology 29:1780-1795.

Cederholm, C. J., M. D. Kunze, T. Murota, AND A. SibATANi. 1999. Pacific salmon car- 
casses: Essential contributions of nutrients and energy for aquatic and terrestrial ecosystems. Fisheries 24(10):6-15.

ChitTy, D. 1960. Population processes in the vole and their relevance to general theory. Canadian Journal of Zoology 38:99-113.

CHiтTY, D. 1967. The natural selection of selfregulating behavior in animal populations. Proceedings of the Ecological Society of Australia 2:51-78.

Ims, R. A., J. HENDEN, AND S. T. KILLENGREEN. 2008. Collapsing population cycles. Trends in Ecology and Evolution 23(2):79-86.

Keith, L. B. 1963. Wildlife's Ten-year Cycle. University of Wisconsin Press, Madison, Wisconsin, USA.

Krebs, C. J., S. Boutin, R. Boonstra, A. R. E. Sinclair, J. N. M. Smith, M. R. T. Dale, K. Martin, and R. Turkington. 1993. Impact of food and predation on the Snowshoe Hare cycle. Science 269:11121115.

LEAN, J. L., AND D. H. RIND. 2009. How will earth's surface temperature change in future decades? Geophysical Research Letters 36, L15708. http://dx.doi.org/10.1029/ 2009GL038932

Millon, A., B. E. Arroyo, And V. BretagNOLLE. 2008. Variable but predictable prey availability affects predator breeding success: Natural versus experimental evidence. Journal of Zoology 275:349-358.

Mossop, D. H. 1988. Winter survival and breeding strategies of Willow Ptarmigan. Pages 330-377 in A. T. Bergerud and M. Gratson (Eds.). Adaptive Strategies and Population Ecology of Northern Grouse. Univerity of Minnesota Press, Minneapolis, Minnesota, USA.

Mossop, D. H. 1994. Trends in Yukon upland gamebird populations from long-term harvest analysis. Transactions of the $59^{\text {th }}$ North American Wildlife and Natural Research Conference: 449-456.

Mossop, D. H., AND R. Hayes. 1982. The Yukon Territory Gyrfalcon harvest experiment (1974-80). Pages 263-280 in W. N. Ladd and P. F. Schempf (Eds.). Proceedings of the Symposium: Raptor Management and Biology in Alaska and Western Canada. US Fish and Wildlife Service, Anchorage, Alaska, USA.

Mossop, D. H., AND R. HAYes. 1994. Long term trends in the breeding density and productivity of Gyrfalcon (Falco rusticolus) in the Yukon Territory, Canada. Pages 403413 in B.-U. Meyburg and R. Chancellor (Eds.). Raptor Conservation Today: Proceedings of the IV World Conference on Birds of Prey and Owls, 10-17 May 1992, Berlin, Germany.

Newton, I. 1979. Population Ecology of Raptors. Buteo Books, Vermillion, South Dakota, USA.

PRIMACK, R. B. 2006. Essentials of Conservation Biology ( $4^{\text {th }}$ ed.). Sinauer Associates, Sunderland, Massachusetts, USA.

Smith, C. A. S., J. C. Miekle, and C. F. Roots. (Eds.) 2004. Ecoregions of the Yukon Territory: Biophysical properties of Yukon landscapes. Agriculture and Agrifood Canada, PARC Technical Bulletin no. 04-01, Summerland, British Columbia, Canada.

Solomon, S., G.-K. Plattner, R. KNutti, AND P. FriedLINGSTEIN. 2009. Irreversible climate change due to carbon dioxide emissions. Proceedings of the National Academy of Sciences 106(6):1704-1709.

Stenseth, N. C., W. FAlCK, O. N. BJoRnstad, AND C. J. KREBS 1997. Population regulation in Snowshoe Hare and Canadian Lynx: Asymmetric food web configurations between hare and lynx. Proceedings of the National Academy of Sciences 94(10):5147-5152.

WeEden, R. B. 1959. Ptarmigan ecology and distribution in western North America. Ph.D. thesis. University of British Columbia, Vancouver, Canada.

WEEDEN, R. B. 1965. Grouse and ptarmigan in Alaska: Their ecology and management. Alaska Department of Fish and Game, Federal Aid in Wildlife Restoration Report, vol. V: Project W-6-R-5, Work Plan 1, Juneau, Alaska, USA. 
- Mossop - 